\title{
ANGPTL4 variants E40K and T266M are associated with lower fasting triglyceride levels and predicts cardiovascular disease risk in Type 2 diabetic Tunisian population
}

Kaouthar Abid ${ }^{1 *}$, Thouraya Trimeche ${ }^{1}$, Donia Mili ${ }^{1}$, Mohamed Amine Msolli ${ }^{2}$, Imen Trabelsi ${ }^{3}$, Semir Nouira ${ }^{2}$ and Abderraouf Kenani ${ }^{1}$

\begin{abstract}
Background: Angiopoietin-like protein 4 (ANGPTL4) is a metabolic factor that increases plasma triglyceride levels by inhibiting lipoprotein lipase (LPL). The objective of this study was to investigate the association of ANGPTL4 variants (E40K and T266M) with triglyceride levels and with cardiovascular risk factors, such as metabolic syndrome (MetS) and obesity in type 2 diabetic Tunisian population.

Methods: We investigated the effect of the tagging single nucleotide polymorphisms (SNPs) rs1044250 (T266M) and rs116843064 (E40K) with triglyceride (TG) levels and CAD risk factors in a cohort of 220 patients undergoing coronary angiography for the evaluation of stable CAD, all of whom had (type 2 diabetes) T2D and were at least overweight. Multivariate logistic regressions were performed on association studies.

Results: $\Pi$ genotype of rs1044250 (T266M variant) showed a protective effect on CVD risk in CAD group patients (OR 1.92, $95 \% \mathrm{Cl} 0.601 .42, p=0.05$ ) compared with control Group patients (OR 1.17, $95 \% \mathrm{Cl} 0.70-1.66, p=0.72$ ). Likewise, GA genotype of rs116843064 (E40K variant): (OR 0.74, $95 \% \mathrm{Cl} 0.54-1.65, p=0.01$ ) for the CAD group compared with control Group patients (OR 1.12, $95 \% \mathrm{Cl} 0.68-1.74, p=0.074$ ).
\end{abstract}

Conclusions: ANGPTL4 variants are associated with, not only lower fasting triglyceride levels, but also a decreased cardiovascular risk in T2D Tunisian patients. So, T266M and E40K polymorphism predicts cardiovascular disease risk in Type 2 diabetic Tunisian population

Keywords: Angiopoietin-like protein 4, CVD risk factors, Coronary artery disease, Metabolic syndrome, Obesity, TG levels

\section{Background}

The angiopoietin-like protein 4 (ANGPTL4) peptide, is a well established regulator of LPL activity and triglyceride levels. In vitro studies confirm that Angptl4, acting as an oligomer, inhibits enzymatic hydrolysis of triglycerides by preventing LPL dimerization [1]. ANGPTL4 has two common coding single nucleotid polymorphisms (cSNPs): E40K and T266M. The E40K substitution prevents

\footnotetext{
*Correspondence: kaouthar_abid@yahoo.fr

'Laboratory of biochemistry, UR 12ES08, Faculty of Medicine, 5000 Monastir, Tunisia

Full list of author information is available at the end of the article
}

Angpt14 oligomer formation, which leads to reduced Angptl4 mediated inhibition of LPL activity [2].

Studies in large Western and Asian population cohorts have proved an independent association between elevated triglyceride levels and CVD risk [3, 4].

ANGPTL4 concentration has a positive correlation with TG in patients with the metabolic syndrome [5]. A cohort study described a significant negative correlation between HDL-cholesterol and ANGPTL4 [5, 6]. Therefore, ANGPTL4 could be associated with disorders of lipid metabolism. This is also supported by human genetic data including genome wide association studies [7]. 
Population-based [8] studies and results in over 30,000 individuals from non-diabetic [7] have confirmed To date, that the E40K loss-of-function variant is associated with significantly lower triglyceride levels $[7,8]$. In contrast, the ANGPTL4 T266M cSNP, which is more prevalent than $\mathrm{E} 40 \mathrm{~K}$, has been shown to have a smaller effect on triglyceride levels in non-diabetic populations [8].

The purpose of this study is to determine whether the ANGPTL4 E40K and T266M polymorphisms are associated with triglyceride levels in well characterized patients with T2D, and with CVD risk factors, such as metabolic syndrome and obesity in type 2 diabetic Tunisian population.

\section{Methods}

\section{Patients}

A total of 220 type 2 diabetic patients, recruited through the Fattouma Bourguiba hospital (Monastir, Tunisia), were diagnosed by angiography. Subjects were defined with cardiovascular disease (CAD) when presenting a stenosis $>50 \%$ in at least one major coronary artery. Subjects were defined without coronary artery disease (No CAD) when presenting a stenosis $<50$ in at least one major coronary artery. Hypertension was diagnosed as a blood pressure of higher than 140/90 $\mathrm{mmHg}$, which was measured according to guidelines [9] and/or the current use of anti-hypertensive drugs. Diabetic subjects were defined by a fasting plasma glucose $>7.0 \mathrm{mmol} /$ $\mathrm{L}$, or by the use of anti-diabetic drugs [10]. Obese subjects were defined by a BMI $>30.0 \mathrm{Kg} / \mathrm{m} 2$. Data on age, sex, smoking, and smoking history were collected from the participants' medical records or by direct interviews. Fasting concentrations of TC, TG, LDL-C, and HDL-C were measured using standard methods [11]. The metabolic syndrome (MetS) was diagnosed when at least three of the following criteria applied: triglycerides $\geq 150 \mathrm{mg} / \mathrm{dl}$ (1.7 mmol/l), high density lipoprotein (HDL) cholesterol $<40 \mathrm{mg} / \mathrm{dl}(1.0 \mathrm{mmol} / \mathrm{l})$ in men and $<50 \mathrm{mg} / \mathrm{dl}$ $(1.3 \mathrm{mmol} / \mathrm{l})$ in women, blood pressure $\geq 130 / \geq 85 \mathrm{~mm}$ $\mathrm{Hg}$, or fasting glucose $\geq 100 \mathrm{mg} / \mathrm{dl}(5.6 \mathrm{mmol} / \mathrm{l})$. This study was approved by our hospital ethical committee chaired by Pr Fekri Abroug, the reported investigations have been carried out in accordance with the principles of the Declaration of Helsinki as revised in 2008. All participants were of Tunisian origin and gave their informed consent for this study.

\section{Biochemical analysis}

Blood samples were taken for biochemical analysis following overnight fasting. Tch, triglyceride and HDL-c concentrations were determined at accredited clinical laboratories using routine clinical methods. LDL cholesterol concentrations were calculated using the Friedewald equation [12].

\section{DNA analysis}

Genomic DNA was prepared from white blood cells using the salting-out method [13]. Genotypes for the variant 9 p21.3 were determined by polymerase chain reaction (PCR) amplification with fluorescent-labeled primers.

\section{Genotyping \\ T266M polymorphism}

This polymorphism was genotyped using the PCR-RFLP (restriction fragment length polymorphism) method. Primer sequences are: forward primer: 5'- TGC CTC ATG GAG TGG CCT CT-3' and reverse primer : 5'-TGT CCT CGC CAC CCA GGT-3'. Amplification was performed in a total reaction volume of $20 \mu \mathrm{l}$ each, containing $0.2 \mu \mathrm{M}$ deoxynucleotide triphosphates, $1 \times$ Taq buffer, $3 \mathrm{mM}$ $\mathrm{MgCl} 2,0.2 \mu \mathrm{M}$ forward primer, $0.2 \mu \mathrm{M}$ reverse primer and 1.0 U Taq polymerase. Thermocycling consisted of an initial denaturation step of $94{ }^{\circ} \mathrm{C}$ for 4 min followed by 35 cycles of $94{ }^{\circ} \mathrm{C}$ for $1 \mathrm{mn} \mathrm{s}, 61^{\circ} \mathrm{C}$ for $30 \mathrm{~s}, 72{ }^{\circ} \mathrm{C}$ for $40 \mathrm{~s}$ and a final extension cycle of $72{ }^{\circ} \mathrm{C}$ for $7 \mathrm{~min}$. The amplified products consisting of a $165 \mathrm{bp}$ fragment was electrophoretically separated on $2 \%$ agarose gels. The PCR products were digested with restriction enzyme NlaIII and incubated at $37{ }^{\circ} \mathrm{C}$ during one night. The digested products consisting of: $156+9 \mathrm{bp}$ for $\mathrm{C}$ allele and $94+62+9 \mathrm{bp}$ for $\mathrm{T}$ allele were analyzed on $3 \%$ agarose gel.

\section{E40K polymorphism}

Allele specific primers for the ancestral $(G)$ and derived (A) alleles of rs1333049: G > A, were designed to selectively amplify the relevant target sequences [14]. The sequence of the forward primer for the $G$ allele was: 5 ' CTT TGC GTC CTG GGA CGA-3' and for A allele the sequence was: 5'-GCT TTG CGT CCT GGG ACA-3'. The internal control primer sequence was: $5^{\prime}$-TGA TCC GAT TCT TTC CAG C-3'. For all the forward primers a common reverse primer was used, with the sequence: 5'-GGC TCT CCT GGC TTG GAA G-3'. Amplification of ancestral and derived alleles was performed separately in a total reaction volume of $20 \mu \mathrm{l}$ each, containing $0.2 \mu \mathrm{M}$ deoxynucleotide triphosphates, $1 \times$ Taq buffer, $3 \mathrm{mM} \mathrm{MgCl} 2,0.2 \mu \mathrm{M}$ allele specific forward primer, $0.3 \mu \mathrm{M}$ reverse primer, $0.1 \mu \mathrm{M}$ internal control primer and 1.0 U Taq polymerase. Thermocycling consisted of an initial denaturation step of $94{ }^{\circ} \mathrm{C}$ for 4 min followed by 35 cycles of $94{ }^{\circ} \mathrm{C}$ for $1 \mathrm{mn} \mathrm{s}, 61{ }^{\circ} \mathrm{C}$ for $30 \mathrm{~s}, 72{ }^{\circ} \mathrm{C}$ for $40 \mathrm{~s}$ and a final extension cycle of $72{ }^{\circ} \mathrm{C}$ for $7 \mathrm{~min}$. The amplified products consisting of a 222 and $223 \mathrm{bp}$ fragment for the allele specific primers ( $G$ and A respectively) and $508 \mathrm{bp}$ for the internal control were electrophoretically separated on $2 \%$ agarose gels.

DNA bands were visualized by UV trans-illumination, the image documented using the BioCap MW software 
(ver. 11.01, Vilber Lourmat, France) and the genotype data were then calculated.

\section{Statistical analyses}

All statistical analysis was performed using version 11.0 of the Statistical Package for the Social Sciences: SPSS (SPSS Inc., Chicago, Illinois, USA). Continuous variables are presented as mean (95\% confidence intervals), and categorical data are summarized as frequencies or percentages. Normal distribution of continuous variables was evaluated with the Kolmolgorov-Smirnov test, and differences among groups were analyzed by one-way analysis of variance (ANOVA). For categorical variables, differences between groups were evaluated by the chisquare test. Odds ratios (ORs) of CAD for TT genotype on rs1044250 (T266M variant) and GA genotype on rs116843064 (E40K variant), and other risk factors, were estimated by multivariate logistic regression analyses. The significance of multiplicative interactions between TT genotype (T266M variant) and GA genotype (E40K variant) and covariates was determined by a Logistic regression model. The relationship between genotype and cardiovascular disease was evaluated with the Mann-Whitney U-test. A 2-sided probability level of $\leq 0.05$ was considered significant.

\section{Results}

Baseline characteristics of the study population

Table 1 shows clinical features of control group (with No CAD) and CAD group. Compared to control group, patients of the CAD group have an increased percentage of obesity, MetS, hypertension, insulin and BMI, TG, and LDL-C levels (all $p<0.05$ ). No significant differences in age, sex, smoking, fasting plasma glucose, HbA1c and HDL-C levels were found between the groups (all $p>0.05)$.

Association between rs116843064 polymorphism (E40K), biochemical measurements and Clinical features

Biochemical measurements and clinical features with respect to various genotypes are listed in Table 2 .

There are no differences between the two genotypes in the control group (all $p>0.005$ ) except the TG level, it's lower in the heterozygote EK $(p<0.05)$. This genotype has a larger effect in the CAD group, showing lower BMI value, obesity and MetS percentages (all $p<0.05$ ) and especially lower TG levels $(p<0.001)$, compared to EE homozygote. No differences were found in age, sex, insulin percentages, fasting plasma glucose, $\mathrm{HbA1C}, \mathrm{TC}$, HDL-C and LDL-C levels between the two genotypes of rs116843064 polymorphism.

\section{Association between rs1044250 polymorphism (T266M), biochemical measurements and Clinical features}

As shown on Table 3, among the three genotypes, there are no differences in age, sex, hypertension, insulin percentages, fasting plasma glucose, HbA1C, TC, HDL-C and LDL-C values between the two groups (all $p>0.05$ ). Compared to control group, there is a significant linear decrease in the BMI value, obesity and MetS percentages

Table 1 Baseline characteristics of the study population

\begin{tabular}{llll}
\hline & Control group (No CAD) Mean(95\% Cl) & CAD Mean $(95 \% \mathrm{Cl})$ & 103 \\
\hline N & 117 & $66,13(64,21-68,07)$ & - \\
Age (years) & $63,94(62,1-65,78)$ & 52,4 & 0,10 \\
Sex (\%men) & 48,7 & 44,7 & 0,62 \\
Smoking (\%) & 26,5 & $12(10,96-13,05)$ & 0,27 \\
Fasting plasma glucose (mmol/L) & $11,48(10,59-12,36)$ & $11,01(10,11-11,91)$ & 0,44 \\
HbA1c (mmol/L) & $10,48(9,72-11,23)$ & $36,23(30,41-45,06)$ & 0,37 \\
BMI (kg/m2) & $29,91(29,14-34,67)$ & 61,2 & 0,02 \\
Obesity (\%) & 42,7 & 52,4 & 0,02 \\
Metabolic syndrome (\%) & 26,5 & $145,68(139,99-151,37)$ \\
SBP (mm/Hg) & $144,78(138,94-150,63)$ & $87,60(83,21-92)$ & $<0,001$ \\
DBP(mm/Hg) & $78(74,71-81,29)$ & 75,7 & 0,82 \\
Hypertension (\%) & 52,1 & $4,87(4,63-5,11)$ & 0,001 \\
TC (mmol/L) & $4,8(4,6-5)$ & $2,90(2,62-3,17)$ & $<0,001$ \\
TG (mmol/L) & $1,71(1,51-1,91)$ & $1,21(1,10-1,33)$ & 0,63 \\
HDL-C (mmol/L) & $1,33(1,24-1,41)$ & $4,40(4,08-4,71)$ & $<0,001$ \\
LDL-C (mmol/L) & $3,22(3-3,44)$ & 77,7 & 0,10 \\
Insulin (\%) & 40,2 & $<0,001$ & $<0,001$ \\
\hline
\end{tabular}

Data presented is mean (95\% confidence intervals) 
Table 2 Association between rs116843064 (E40K) polymorphism, biochemical measurements and clinical features

\begin{tabular}{|c|c|c|c|c|c|c|}
\hline & \multicolumn{3}{|c|}{ Control group Mean(95 \% Cl) } & \multicolumn{3}{|l|}{ CAD Mean $(95 \%$ Cl) } \\
\hline & $\mathrm{EE}(\mathrm{GG})$ & EK (GA) & $\mathrm{p}$ & $\mathrm{EE}(\mathrm{GG})$ & EK (GA) & $\mathrm{p}$ \\
\hline $\mathrm{N}$ & 105 & 12 & - & 74 & 28 & - \\
\hline Age (years) & $63,48(61,53-65,44)$ & $67,92(61,97-73,87)$ & 0,22 & $65,73(63,43-68,03)$ & $67,1(63,24-70,98)$ & 0,5 \\
\hline Sex (\%men) & 46,7 & 66,7 & 0,78 & 50 & 60,7 & 0,43 \\
\hline Fasting plasma glucose (mmol/L) & $11,56(10,64-12,49)$ & $10,74(7,20-14,28)$ & 0,26 & $12,52(11,32-13,73)$ & $10,48(8,34-12,61)$ & 0,11 \\
\hline $\mathrm{HbA1c}(\mathrm{mmol} / \mathrm{L})$ & $10,55(9,76-11,34)$ & $9,85(6,82-12,88)$ & 0,22 & $11,49(10,42-12,56)$ & $9,57(7,87-11,27)$ & 0,08 \\
\hline $\mathrm{BMI}(\mathrm{kg} / \mathrm{m} 2)$ & $31,6(28,34-34,87)$ & $29,71(28,93-30,49)$ & 0,05 & $41,47(31,94-45)$ & $31,16(30,15-32,17)$ & 0,02 \\
\hline Obesity (\%) & 50 & 41,9 & 0,06 & 75,4 & 58,1 & 0,03 \\
\hline Metabolic syndrome (\%) & 26,7 & 25 & 0,12 & 47,3 & 67,9 & $<0,001$ \\
\hline $\mathrm{SBP}(\mathrm{mm} / \mathrm{Hg})$ & $144,63(138,68-150,58)$ & $146,17(119,19-173,14)$ & 0,062 & $144,44(136,97-151,92)$ & $148,14(140,8-155,48)$ & 0,49 \\
\hline $\mathrm{DBP}(\mathrm{mm} / \mathrm{Hg})$ & $78,13(74,77-81,49)$ & $76,83(61,87-91,8)$ & 0,08 & $87,32(82,10-92,55)$ & 87,89(78,99-96,8) & 0,84 \\
\hline Hypertension (\%) & 51,4 & 58,3 & 0,64 & 71,6 & 85,7 & 0,12 \\
\hline $\mathrm{TC}(\mathrm{mmol} / \mathrm{L})$ & $4,79(4,58-5)$ & $4,87(4,15-5,6)$ & 0,27 & $4,73(4,44-5,03)$ & $5,18(4,76-5,61)$ & 0,06 \\
\hline $\mathrm{TG}(\mathrm{mmol} / \mathrm{L})$ & $1,72(1,51-1,94)$ & $1,59(1,21-1,97)$ & 0,01 & $1,9(1,59-2,2)$ & $1,65(1,19-2,32)$ & $<0,001$ \\
\hline $\mathrm{HDL}-\mathrm{C}(\mathrm{mmol} / \mathrm{L})$ & $1,32(1,23-1,41)$ & $1,43(1,19-1,67)$ & 0,07 & $1,21(1,06-1,35)$ & $1,23(1,03-1,44)$ & 0,08 \\
\hline LDL-C (mmol/L) & $3,2(2,97-3,44)$ & $3,36(2,69-4,03)$ & 0,06 & $4,36(3,99-4,73)$ & $4,34(3,78-5,09)$ & 0,07 \\
\hline Insulin (\%) & 41 & 33,3 & 0,33 & 75,7 & 82,1 & 0,44 \\
\hline
\end{tabular}

Data presented is mean (95\% confidence intervals)

among the three genotypes in the CAD group, these values are significantly lower in MM genotype carriers. Concerning the TG level, MM genotype has a significant lowering effect in the control group $(p=0.04)$, but this effect is larger in CAD group $(p=0.01)$.

\section{Comparison between E40K and T266M effect on TG levels} Tables 2 and 3 show that the association of E40K and T266M with triglyceride levels remained significant in the two groups ( $p=0.01$ and $p=0.04$ respectively), but the association is more significant in the CAD group ( $p$ $<0.001$ and $p=0.01$ respectively), and as shown E40K polymorphism has a larger effect in TG levels than T266M polymorphism.

\section{Multivariable analysis}

A multiple logistic regression analysis was performed with CAD as the dependent variable (Table 4). Analysis showed that TT genotype of rs1044250 (T266M variant) showed a protective effect on CVD risk in CAD group patients (OR 1.92, $95 \%$ CI 0.60-1.42, $p=0.05$ ) compared with control Group patients (OR 1.17, 95 \% CI 0.70$1.66, p=0.72)$. Likewise, GA genotype of rs116843064 (E40K variant): (OR 0.74, 95 \% CI 0.54-1.65, p =0.01) for the CAD group compared with control Group patients (OR 1.12, $95 \%$ CI 0.68-1.74, $p=0.074$ ). So, the two genotypes of ANGPTL4 variants play a protective role against CVD in Tunisian type 2 diabetic patients.

\section{Discussion}

The principal findings of this study are a confirmation of an association of the E40K and T266M variants with lower TG levels and predicts cardiovascular disease risk in 220 Type 2 diabetic individuals. These results are partly in agreement with the findings of Talmud et al. [8] who examined 6 ANGPTL4 SNPs and reported that E40K was associated with increased CVD risk and T266M showed effects only under conditions of postprandial stress. But the functionality of these potential "loss-of-function" variants needs validation.

Formation of Angptl4 oligomers by disulphide bonds in the coiled-coil N-terminus [15] is required to inhibit LPL activity. The E40K substitution destabilizes the protein after secretion, preventing the extracellular accumulation of oligomers and abolishing the ability of the Angptl4 protein to inhibit LPL activity [2].

Variant rs1044250 (T266M) is located in the Cterminal region of ANGPTL4 and is conserved across human, rat, and mouse species, supporting a functional role $[5,16-18]$. Thus, it may be assumed that rs1044250 may influence cardiovascular risk by decreasing ANGPTL4 activity in endothelial cells increasing angiogenesis and vascular permeability.

Smart-Haljko et al. [19] demonstrate for the first time that the ANGPTL4 E40K and T266M variants are associated with lower triglyceride levels in the setting of T2D. In addition, their findings demonstrate that ANGPTL4 genotype status does not alter triglyceride response to a lifestyle intervention in the Look AHEAD 
Table 3 Association between rs116843064 (T266M) polymorphism, biochemical measurements and clinical features

\begin{tabular}{|c|c|c|c|c|c|c|c|c|}
\hline & \multicolumn{4}{|l|}{ No CAD } & \multicolumn{4}{|l|}{ CAD } \\
\hline & $\pi$ & TM & MM & $\mathrm{p}$ & $\pi$ & TM & MM & $\mathrm{p}$ \\
\hline $\bar{N}$ & 62 & 40 & 5 & - & 32 & 55 & 16 & - \\
\hline Age (years) & $66,18(63,02-69,35)$ & $63,54(62,11-65,92)$ & $59,84(55-64,69)$ & 0,06 & $67,14(64,11-70,18)$ & $65,37(62,38-68,38)$ & $65,62(60,12-71,13)$ & 0,11 \\
\hline Sex (\%men) & 47,7 & 45,2 & 57,9 & 0,65 & 57,1 & 44,4 & 62,5 & 0,62 \\
\hline Fasting plasma glucose (mmol/L) & $10,7(8,43-12,97)$ & $11,56(10,13-12,99)$ & $11,69(10,16-13,23)$ & 0,74 & $11,31(8,91-13,71)$ & $11,7(10-13,4)$ & $12,53(10,86-14,2)$ & 0,12 \\
\hline $\mathrm{HbA1c}(\mathrm{mmol} / \mathrm{L})$ & $10,18(8,08-12,27)$ & $10,61(9,37-11,85)$ & $11,01(9,68-12,34)$ & 0,76 & $10,36(8,09-12,64)$ & $10,73(9,4-12,07)$ & $11,49(9,98-13)$ & 0,76 \\
\hline BMI (kg/m2) & $30,91(29,35-32,46)$ & $29,62(28,59-30,64)$ & $29,44(27,62-31,26)$ & 0,27 & $42,32(40,83-43,80)$ & $39,94(38,78-41,09)$ & $32,03(30,68-33,37)$ & 0,01 \\
\hline Obesity (\%) & 52,6 & 47,7 & 48,1 & 0,08 & 81,3 & 69 & 46,7 & 0,02 \\
\hline Metabolic syndrome (\%) & 26,2 & 27,3 & 26,8 & 0,21 & 62,5 & 51,9 & 41,94 & 0,01 \\
\hline $\mathrm{SBP}(\mathrm{mm} / \mathrm{Hg})$ & $149,33(137,59-161,08)$ & $146,22(137,78-154-67)$ & $137,05(121,5-152,6)$ & 0,40 & $148,69(139,3-158,08)$ & $143,62(134,51-152,74)$ & $143,56(131,21-155 ; 92)$ & 0,16 \\
\hline $\mathrm{DBP}(\mathrm{mm} / \mathrm{Hg})$ & $82,59(76,56-88,64)$ & $75,15(68,69-81,62)$ & $75,13(69,34-80,94)$ & 0,13 & $90,42(82,99-97,86)$ & $83,97(77,06-90,9)$ & $90,37(81,87-98,88)$ & 0,17 \\
\hline Hypertension (\%) & 59,1 & 57,1 & 55,1 & 0,28 & 70 & 75 & 81,4 & 0,06 \\
\hline $\mathrm{TC}(\mathrm{mmol} / \mathrm{L})$ & $4,55(4,21-4,89)$ & $4,87(4,58-5,16)$ & $5,3(4,7-5,9)$ & 0,44 & $4,71(4,18-5,24)$ & $4,81(4,43-5,2)$ & $4,98(4,59-5,38)$ & 0,36 \\
\hline $\mathrm{TG}(\mathrm{mmol} / \mathrm{L})$ & $1,98(1,4-2,56)$ & $1,75(1,41-2,09)$ & $1,55(1,23-1,86)$ & 0,04 & $2,53(2,47-3,19)$ & $2,83(1,83-3,84)$ & $3,23(2,53-3,45)$ & 0,01 \\
\hline $\mathrm{HDL}-\mathrm{C}(\mathrm{mmol} / \mathrm{L})$ & $1,3(1,06-1,54)$ & $1,31(1,16-1,45)$ & $1,41(1,28-1,55)$ & 0,49 & $1,15(0,94-1,36)$ & $1,19(0,99-1,40)$ & $1,25(1,07-1,43)$ & 0,68 \\
\hline LDL-C (mmol/L) & $2,77(2,48-3,06)$ & $3,31(2,94-3,68)$ & $3,01(2,46-4,55)$ & 0,31 & $3,25(3,07-1,43)$ & $4,51(3,54-5,49)$ & $4,74(4,24-5,24)$ & 0,09 \\
\hline Insulin (\%) & 46,2 & 45,4 & 45,5 & 0,12 & 51,4 & 61,3 & 62,2 & 0,09 \\
\hline
\end{tabular}

Data presented is mean $(95 \%$ confidence intervals) 
Table 4 Multivariable logistic regression analysis

\begin{tabular}{|c|c|c|c|c|c|c|}
\hline & \multicolumn{3}{|c|}{ Control group } & \multicolumn{3}{|l|}{ CAD } \\
\hline & $\overline{\mathrm{OR}}$ & $95 \% \mathrm{Cl}$ & $p$ & $\overline{\mathrm{OR}}$ & $95 \% \mathrm{Cl}$ & $p$ \\
\hline \multicolumn{7}{|l|}{ T266M : } \\
\hline $\begin{array}{l}\text { rs } 1044250 \\
\text { (TT vs. non TT) }\end{array}$ & 1,17 & $0,70-1,66$ & 0,72 & 0,92 & $0,60-1,42$ & 0,05 \\
\hline \multicolumn{7}{|l|}{ E40K : } \\
\hline $\begin{array}{l}\text { rs116843064 } \\
\text { (GA vs. GG) }\end{array}$ & 1,12 & $0,68-1,74$ & 0,074 & 0,74 & $0,54-1,65$ & 0,01 \\
\hline
\end{tabular}

study. The T266M TG effect is consistent with the European Atherosclerosis Research Study II CHD offspring study which showed that MM homozygotes had enhanced triglyceride clearance following an oral fat tolerance test [8].

Our findings are confirmed by another study of Muendlein et al. [20], they showed a positive association of circulating ANGPTL4 levels as well as of ANGPTL4 SNPs with future cardiovascular risk in angiographically characterized coronary patients.

\section{Conclusion}

ANGPTL4 variants are associated with, not only lower fasting triglyceride levels, but also a decreased cardiovascular risk in T2D Tunisian patients.

\section{Availability of data and materials}

We do not wish to share our data, they are confidential to our research unit.

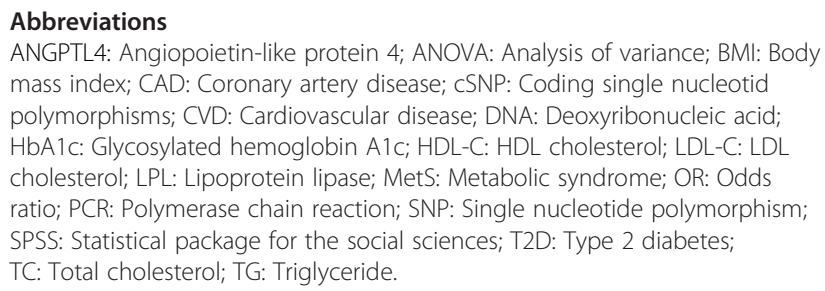

Abbreviations

ANGPTL4: Angiopoietin-like protein 4; ANOVA: Analysis of variance; BMI: Body mass index; CAD: Coronary artery disease; CSNP: Coding single nucleotid polymorphisms; CVD: Cardiovascular disease; DNA: Deoxyribonucleic acid; HbA1c: Glycosylated hemoglobin A1c; HDL-C: HDL cholesterol; LDL-C: LDL cholesterol; LPL: Lipoprotein lipase; MetS: Metabolic syndrome; OR: Odds ratio; PCR: Polymerase chain reaction; SNP: Single nucleotide polymorphism; SPSS: Statistical package for the social sciences; T2D: Type 2 diabetes; TC: Total cholesterol; TG: Triglyceride.

\section{Competing interests}

The authors declare that they have no competing interests.

\section{Author's contributions}

AK and MD carried out the molecular genetic studies, participated in the sequence alignment and drafted the manuscript. AK carried out the immunoassays. TT and TI participated in the sequence alignment. AK participated in the design of the study and performed the statistical analysis. MMA, NS and KA conceived of the study, and participated in its design and coordination and helped to draft the manuscript. All authors read and approved the final manuscript.

\section{Acknowledgement}

None.

\section{Funding}

No funding received.

\section{Author details}

'Laboratory of biochemistry, UR 12ES08, Faculty of Medicine, 5000 Monastir, Tunisia. ${ }^{2}$ Emergency Medicine, F. Bourguiba University Hospital, Monastir, Tunisia. ${ }^{3}$ Research Unit: UR 12 ES09 Dyslipidemia and Atherogenesis, Faculty of Medicine, Monastir 5000, Tunisia.

Received: 1 March 2016 Accepted: 17 March 2016

Published online: 23 March 2016

\section{References}

1. Sukonina V, Lookene A, Olivecrona T, Olivecrona G. Angiopoietin-like protein 4 converts lipoprotein lipase to inactive monomers and modulates lipase activity in adipose tissue. Proc Natl Acad Sci U S A. 2006;103(46):17450-5.

2. Yin W, Romeo S, Chang S, Grishin NV, Hobbs HH, Cohen JC. Genetic variation in ANGPTL4 provides insights into protein processing and function. J Biol Chem. 2009;284(19):13213-22.

3. Boekholdt SM, Khaw KT, Gudnason V. Triglycerides and the risk of coronary heart disease: 10,158 incident cases among 262,525 participants in 29 Western prospective studies. Circulation. 2007;115(4):450-8.

4. Patel A, Barzi F, Jamrozik K, Lam TH, Ueshima H, Whitlock G, Woodward M. Serum triglycerides as a risk factor for cardiovascular diseases in the Asia-Pacific region. Circulation. 2004;110(17):2678-86.

5. Stejskal D, Karpisek M, Reutova H, Humenanská V, Petzel M, Kusnierová $P$, Vareka I, Vareková R, Stejskal P. Angiopoietin-like protein 4: development, analytical characterization, and clinical testing of a new ELISA. Gen Physiol Biophys. 2008;27:59-63.

6. Smart-Halajko MC, Robciuc MR, Cooper JA, Jauhiainen M, Kumari M, Kivimaki M, Khaw KT, Boekholdt SM, Wareham NJ, Gaunt TR, Day IN, Braund PS,Nelson CP, Hall AS, Samani NJ, Humphries SE, Ehnholm C, Talmud PJ. The relationship between plasma angiopoietin-like protein 4 levels, angiopoietin-like protein 4 genotype, and coronary heart disease risk. Arterioscler Thromb Vasc Biol. 2010;30:2277-82.

7. Romeo S, Pennacchio LA, Fu Y, Boerwinkle E, Tybjaerg-Hansen A, Hobbs HH, Cohen JC. Population-based resequencing of ANGPTL4 uncovers variations that reduce triglycerides and increase HDL. Nat Genet. 2007;39:513-6.

8. Talmud PJ, Smart M, Presswood E, Cooper JA, Nicaud V, Drenos F, Palmen J, Marmot MG, Boekholdt SM, Wareham NJ, Khaw KT, Kumari M, Humphries SE, EARSII Consortium, HIFMECH Consortium. ANGPTL4 E40K and T266M: effects on plasma triglyceride and HDL levels, postprandial responses, and CHD risk. Arterioscler Thromb Vasc Biol. 2008;28(12):2319-25. doi:10.1161/ATVBAHA.108.176917.

9. Mancia G, De Backer G, Dominiczak A, Cifkova R, Fagard R, Germano G, Grassi G, Heagerty AM, Kjeldsen SE, Laurent S, Narkiewicz K, Ruilope L,Rynkiewicz A, Schmieder RE, Boudier HA, Zanchetti A, Vahanian A, Camm J, De Caterina R, Dean V, Dickstein K, Filippatos G, Funck-Brentano C, Hellemans I, Kristensen SD, McGregor K, Sechtem U, Silber S, Tendera M, Widimsky P, Zamorano JL, Erdine S, Kiowski W, Agabiti-Rosei E, Ambrosioni E, Lindholm LH,Viigimaa M, Adamopoulos S, Agabiti-Rosei E, Ambrosioni E, Bertomeu V, Clement D, Erdine S, Farsang C, Gaita D, Lip G, Mallion JM, Manolis AJ, Nilsson PM, O'Brien E, Ponikowski P, Redon J, Ruschitzka F, Tamargo J, van Zwieten P, Waeber B, Williams B. Management of Arterial Hypertension of the European Society of Hypertension; European Society of Cardiology. Management of Arterial Hypertension of the European Society of Hypertension; European Society of Cardiology. 2007 Guidelines for the Management of Arterial Hypertension: The Task Force for the Management of Arterial Hypertension of the European Society of Hypertension (ESH) and of the European Society of Cardiology (ESC). J Hypertens. 2007;25:1105-87.

10. Wang JG, Staessen JA, Franklin SS, Fagard R, Gueyffier F. Systolic and diastolic blood pressure lowering as determinants of cardiovascular outcome. Hypertension. 2005;45:907-13.

11. Ye S, Willeit J, Kronenberg F, Xu Q, Kiechl S. Association of genetic variation on chromosome 9p21 with susceptibility and progression of atherosclerosis: a population-based, prospective study. J Am Coll Cardiol. 2008;52:378-84.

12. Friedewald WT, Levy Rl, Fredrickson DS. Estimation of the concentration of low-density lipoprotein cholesterol in plasma, without use of the preparative ultracentrifuge. Clin Chem. 1972;6:499-502

13. Miller SA, Dykes DD, Polesky HF. A simple salting out procedure for extracting DNA from human nucleated cells. Nucleic Acids Res. $1988 ; 16: 1215$. 
14. Little S. Amplification-refractory mutation system (ARMS) analysis of point mutations. In: Boyle AL, editor. Current protocols in human genetics. New York: John Wiley \& Sons; 2001. p. 9.8.1-9.8.12.

15. Ge H, Yang G, Yu X, Pourbahrami T, Li C. Oligomerization state-dependent hyperlipidemic effect of angiopoietin-like protein 4. J Lipid Res. 2004;45(11):2071-9.

16. Lei X, Shi F, Basu D, Huq A, Routhier S, Day R, Jin W. Proteolytic processing of angiopoietin-like protein 4 by proprotein convertases modulates its inhibitory effects on lipoprotein lipase activity. J Biol Chem. 2011;286:15747-56.

17. Yoshida K, Shimizugawa T, Ono M, Furukawa H. Angiopoietin-like protein 4 is a potent hyperlipidemia-inducing factor in mice and inhibitor of lipoprotein lipase. J Lipid Res. 2002:43:1770-2.

18. Robciuc MR, Tahvanainen E, Jauhiainen M, Ehnholm C. Quantitation of serum angiopoietin-like proteins 3 and 4 in a Finnish population sample. J Lipid Res. 2010;51:824-31.

19. Smart-Halajko MC, Kelley-Hedgepeth A, Montefusco MC, Cooper JA, Kopin A, McCaffery JM, Balasubramanyam A, Pownall HJ, Nathan DM, Peter I, Talmud PJ, Huggins GS. ANGPTL4 variants E4OK and T266M are associated with lower fasting triglyceride levels in Non-Hispanic White Americans from the Look AHEAD Clinical Trial. BMC Med Genet. 2011;12:89. doi:10.1186/1471-2350-12-89.

20. Muendlein $A$, Saely $C H$, Leiherer $A$, Fraunberger $P$, Kinz E, Rein P, Vonbank $A$, Zanolin D, Malin C, Drexel H. Angiopoietin-like protein 4 significantly predicts future cardiovascular events in coronary patients. Atherosclerosis. 2014;237:632-8.

\section{Submit your next manuscript to BioMed Central} and we will help you at every step:

- We accept pre-submission inquiries

- Our selector tool helps you to find the most relevant journal

- We provide round the clock customer support

- Convenient online submission

- Thorough peer review

- Inclusion in PubMed and all major indexing services

- Maximum visibility for your research

Submit your manuscript at www.biomedcentral.com/submit 